\title{
An Octanuclear Metallosupramolecular Cage Designed to Exhibit Spin-Crossover Behavior
}

\author{
Niklas Struch, ${ }^{[\mathrm{a}]}$ Christoph Bannwarth, ${ }^{[\mathrm{b}]}$ Tanya K. Ronson, ${ }^{[\mathrm{c}]}$ Yvonne Lorenz, ${ }^{[\mathrm{d}]}$ Bernd Mienert, ${ }^{[\mathrm{e}]}$ Norbert \\ Wagner ${ }^{[f]}$ Marianne Engeser, ${ }^{[\mathrm{d]}]}$ Eckhard Bill, ${ }^{[\mathrm{e}]}$ Rakesh Puttreddy, ${ }^{[\mathrm{g}]}$ Kari Rissanen, ${ }^{[\mathrm{g}]}$ Johannes Beck, ${ }^{[\mathrm{fl}}$ \\ Stefan Grimme ${ }^{[b]}$ Jonathan R. Nitschke ${ }^{[c]}$ and Arne Lützen ${ }^{\star[a]}$
}

In memoriam of Prof. Dr. Fritz Vögtle

\begin{abstract}
A series of novel supramolecular octanuclear cages has been synthesized and characterized. Employing the subcomponent self-assembly approach utilizing 5,10,15,20-tetrakis-(4-aminophenyl)porphyrin or 5,10,15,20-tetrakis-(4-aminophenyl)-porphyrin zinc(II), $1 \mathrm{H}$-4-imidazole carbaldehyde and either zinc(II) or iron(II) salts, we were able to prepare $O$-symmetric cages having a confined volume of ca. $1300 \AA^{3}$. The use of iron(II) salts yielded coordination cages in the high spin state at room temperature, manifesting spincrossover in solution at low temperatures, whereas corresponding zinc(II) salts yielded the corresponding diamagnetic analogues. The new cages were characterized using synchrotron X-ray crystallography, temperature dependent NMR as well as 2D NMR experiments, high resolution mass spectrometry, Mössbauer, FT-IR, and UV-Vis spectroscopy. The cage structures and UV-Vis spectra were independently confirmed by state-of-the-art DFT calculations. A remarkably high spin stabilizing effect through encapsulation of $\mathrm{C}_{70}$ was observed. The spin transition temperature $T_{1 / 2}$ is lowered by $20 \mathrm{~K}$ in the host-guest-complex as shown by variable temperature NMR spectroscopy.
\end{abstract}

A major example for the interplay of structure and properties are spin-crossover compounds. These materials, especially those

[a] N. Struch, Prof. A. Lützen

Kekulé-Institut für Organische Chemie und Biochemie

Rheinische Friedrich-Wilhelms-Universität Bonn

Gerhard-Domagk-Str. 1, 53121 Bonn (Germany)

E-mail: arne.luetzen@uni-bonn.de

[b] C. Bannwarth, Prof. S. Grimme

Mulliken Center for Theoretical Chemistry

Rheinische Friedrich-Wilhelms-Universität Bonn Beringstr. 4, 53115 Bonn (Germany)

[c] Dr. T. K. Ronson, Prof. J. R. Nitschke

Department of Chemistry

University of Cambridge

Lensfield Road, Cambridge, CB2 1EW (UK)

[d] Y. Lorenz, Dr. M. Engeser

Kekulé-Institut für Organische Chemie und Biochemie

Rheinische Friedrich-Wilhelms-Universität Bonn

Gerhard-Domagk-Str. 1, 53121 Bonn (Germany)

[e] B. Mienert, Dr. E. Bill

Max-Planck-Institut für Chemische Energiekonversion

Stiftstr. $34-36,45470$, Mülheim a. d. Ruhr (Germany)

[f] Dr. R. Puttreddy, Acad. Prof. K. Rissanen

University of Jyvaskyla

Department of Chemistry, Nanoscience Center

P.O. Box 34, 40014 Jyvaskyla (Finland)

[g] N. Wagner, Prof. J. Beck

Institut für Anorganische Chemie

Rheinische Friedrich-Wilhelms-Universität Bonn

Gerhard-Domagk-Str. 1, 53121 Bonn (Germany)

Supporting information for this article is given via a link at the end of the document. based on iron(II) ions, have been a focus of intense research. ${ }^{[1]}$ While offering a bi-stability between two magnetically and often optically distinguishable states - the diamagnetic low-spin and the paramagnetic high-spin state - they offer the possibility of being used as molecular switches. ${ }^{[2]}$

Following a bottom-up approach ${ }^{[3]}$ towards new materials based on monomeric and polymeric systems, progressively more research groups have investigated the spin-crossover properties of oligonuclear metal complexes. ${ }^{[4]}$ Supramolecular approaches have become increasingly relevant within the field of spincrossover research over the last decade. This is due to the fact, that these approaches offer the possibility of mechanically linking several spin-crossover centers e.g. in dinuclear complexes $^{[5]}$, helicates ${ }^{[6]}$, grids ${ }^{[7]}$ and metallosupramolecular tetrahedra ${ }^{[8]}$, or connecting the spin-crossover centers to f-block elements. ${ }^{[9]}$ Furthermore, it has also been demonstrated that spin-crossover materials can be obtained by incorporation of the active center in a supramolecular cage. ${ }^{[10]}$ However, the synthetic efforts that are necessary to establish suitable ligands to achieve multi-nuclear assemblies with the desired magnetic properties are often very demanding. An alternative means to simplify synthetic and analytical efforts is to apply the subcomponent self-assembly approach. This approach has proven to be a versatile and reliable means to access oligonuclear metallosupramolecular species. ${ }^{[11]}$ Despite recent progress, however, it is still a challenge to design multinuclear iron(II) spin-crossover compounds because of the inherent difficulties in matching the appropriate ligand structure and coordination geometries to achieve the desired magnetic properties. ${ }^{[12,13]}$ Herein, we present a supramolecular octanuclear cage exhibiting spin-crossover behavior in solution. Furthermore, the spin-crossover properties are affected by binding large neutral aromatic guests.

Syntheses of the complexes presented herein followed an established procedure to form the desired complexes using a subcomponent self-assembly ${ }^{[14]}$ of $1 \mathrm{H}$-4-imidazole carbaldehyde, 5,10,15,20-tetra(aminophenyl)porphyrin for $\left[\mathrm{H}_{2}-1\right] \quad(5,10,15,20$-tetra(aminophenyl)porphyrin-Zn(II) for [Zn-1]) and iron(II) triflate hydrate or zinc(II) triflate (Scheme 1 ). Whereas complexes derived from pyridylimines regularly yield the corresponding iron(II) low-spin complexes, imidazolylimines offer a ligand field conducive to the formation of spin-crossover complexes. We chose the larger $\mathrm{C}_{4}$-symmetric porphyrin backbone to establish a large cavity and an overall $O$-symmetry connecting eight spin-crossover centers in the resulting complex. 


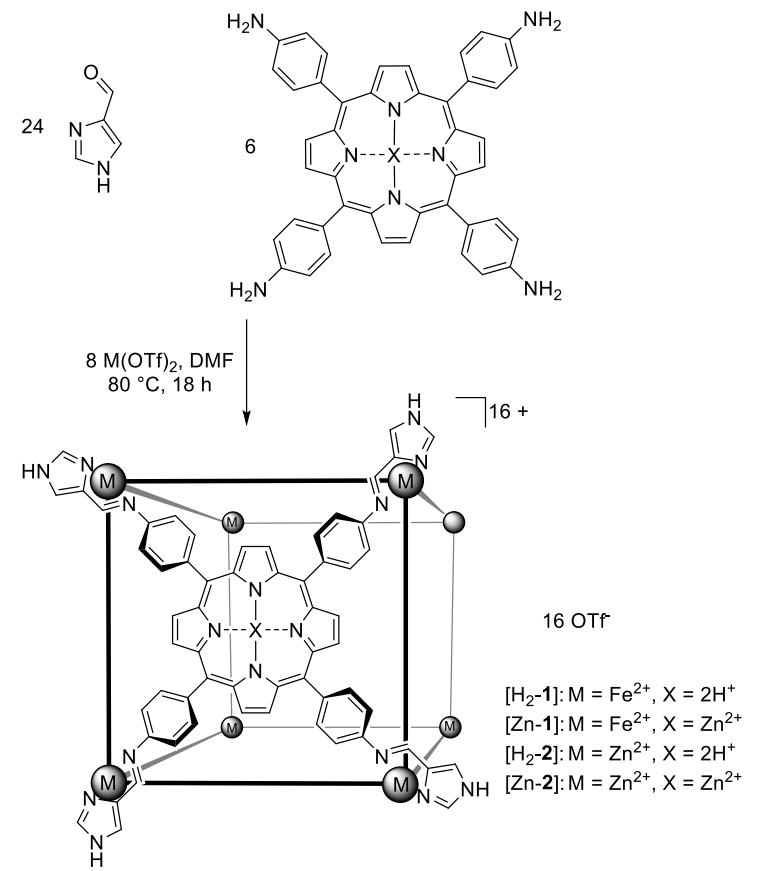

Scheme 1. General scheme representing the synthesis of the octanuclear complexes presented herein with $\mathrm{M}$ being either iron(II) or zinc(II) and $\mathrm{X}$ representing either $\mathrm{H}_{2}$ or $\mathrm{Zn}(\mathrm{II})$.

In general, iron(II) complexes are prone to oxidation. Accordingly, all reactions were carried out in oven-dried Schlenk-tubes under an argon atmosphere in carefully dried and degassed solvents. Nonetheless, the cage complexes were found to be stable for several weeks both in solution (under the synthesis conditions) and in the solid state under ambient conditions. While the observed $\mathrm{O}$-symmetric cage was the major product, purification was necessary, involving vapor diffusion precipitation of the complex from the reaction solution, extraction with acetonitrile and a further vapor diffusion step to yield a dark purple powder in all cases. A small amount of iron(II) triflate hexahydrate was observed as an impurity by Mössbauer spectroscopy (see SI). The molecular composition of the cages was established by high resolution mass spectrometry ( $\mathrm{SI}$ ) and both paramagnetic NMRspectra of the iron cages $\left[\mathrm{H}_{2}-1\right]$ and $[\mathrm{Zn}-1]$ as well as those of the isostructural but diamagnetic zinc analogues $\left[\mathrm{H}_{2}-2\right]$ and $[\mathrm{Zn}$ 2] establish connectivity and point-symmetry $O$ of the metallosupramolecular assemblies (see $\mathrm{SI}$ ). The presence of all functional groups and the expected chromophores was furthermore supported by FT-IR spectroscopy and by comparing experimental and simulated ${ }^{[15]}$ UV/Vis spectra (see $\mathrm{SI}$ ).

Finally, the cubic structure of [Zn-1] was solved by single-crystal synchrotron X-ray diffraction (Figure 1). Suitable single crystals were obtained after several weeks from a mixture of the tetrafluoroborate analogue of [Zn-1] upon addition of excess tetrabutylammonium perrhenate in acetonitrile. The crystal structure of the complex (space group P2 $2_{1}$ ) revealed a closed cage of octahedral symmetry (for a more detailed description see $\mathrm{SI}$ ). NMR spectroscopic data as well as XRD-data indicate the self-assembly process to occur in a completely diastereoselective fashion leading to homochiral cages.

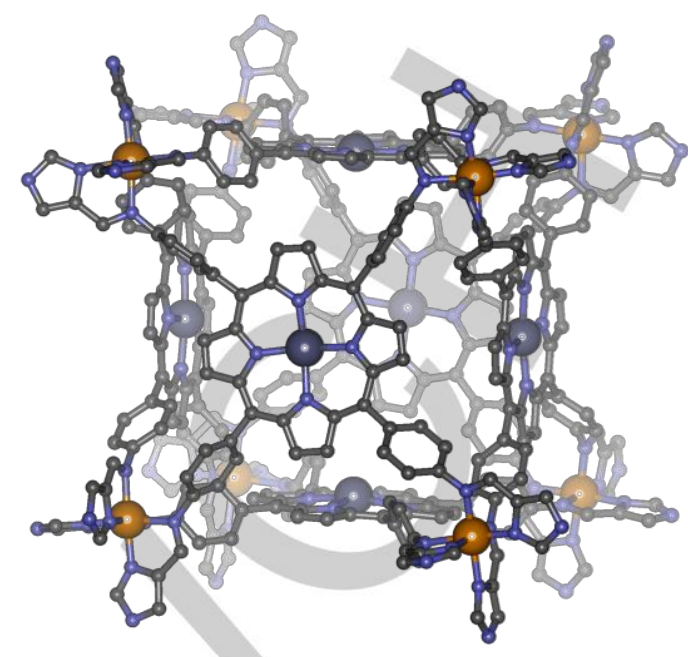

Figure 1. Molecular structure of the cationic part of [Zn-1] as solved by single crystal synchrotron X-ray diffraction analysis, color code: grey - carbon, blue nitrogen, purple - zinc, orange - iron.

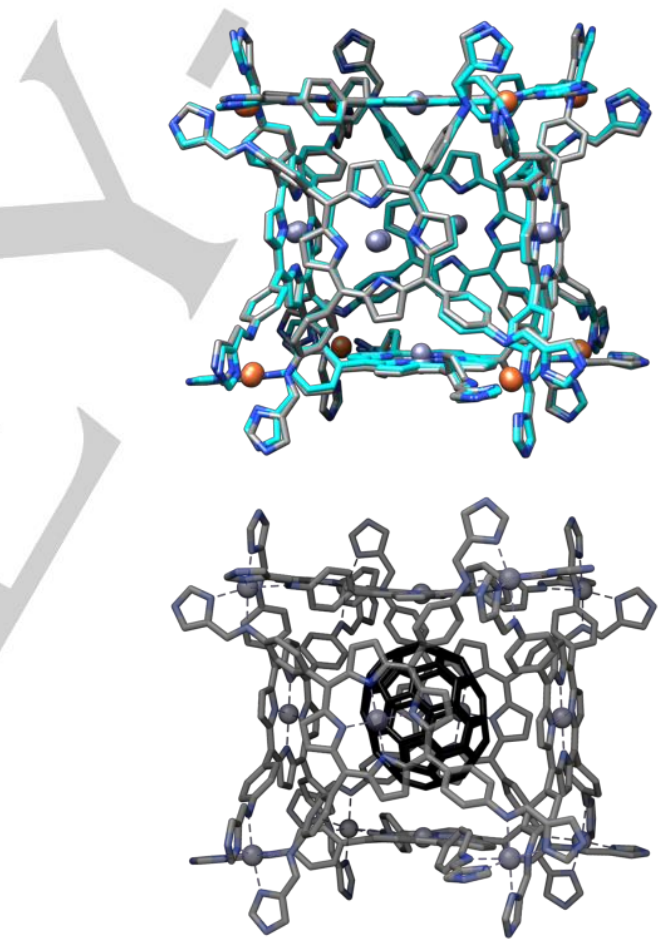

Figure 2: Top: Overlay of the cationic unit of [Zn-1] (cyan) as found by single crystal XRD and the DFT (PBEh-3c ${ }^{[16]}$ ) optimized structure of the cationic units of [Zn-2] (grey) A heavy atom RMSD of $0.31 \AA$ between the two structures is found (counter-ions, solvent molecules, and hydrogen atoms are omitted; color code: cyan/grey - carbon, blue - nitrogen, purple - zinc, orange - iron/zinc (in $[\mathrm{Zn}-1] /[\mathrm{Zn}-2])$. Bottom: DFT optimized structure of the cationic unit of $\mathrm{C}_{70} @[\mathrm{Zn}$ 2] (hydrogen atoms are omitted color code: black, grey - carbon, blue nitrogen, purple - zinc)

The cubic structures of [Zn-2] and $\mathrm{C}_{70} @[\mathrm{Zn}-2]$ were further confirmed by density functional theory (DFT) calculations ${ }^{[16]}$ (see Figure 2 and $\mathrm{SI}$ ). Taking into account that the DFT calculations were performed for $[\mathrm{Zn-2}]$ rather than [Zn-1] the optimization still yields a structure in very good agreement with the experimental one (see Figure 2 top, heavy atom RMSD of $0.31 \AA$ ). 
Furthermore, it revealed that $\geq 80 \%$ of the positive charge $(+16)$ in $[\mathrm{Zn}-2]$ is located on the 14 zinc atoms (see SI). Thus, in solution and in the solid state, it is likely that the six $\mathrm{Zn}$ atoms in the porphyrin groups are additionally coordinated by solvent molecules or counter-ions some of which could be localized in these positions by the XRD analysis.

The six porphyrins cap the faces of the cube shaped inner void, in agreement with previously presented data. ${ }^{[17]}$ The complex hosts a well closed cavity of about $1300 \AA^{3}{ }^{[18]}$ As anticipated, the cavity within the complex can accommodate large aromatic guests. To accomplish complexation within the cavity the guest was added in threefold excess to the reaction mixture. ${ }^{[19]}$ NMRspectroscopy revealed that fullerene $\mathrm{C}_{60}$ is only a moderatelybinding guest as only approx. $50 \%$ of the metallosupramolecular cages' voids were filled with $\mathrm{C}_{60}$; however, the larger $\mathrm{C}_{70}$ fullerene proved to be a good guest (see $\mathrm{SI}$ ). This difference can be rationalized by comparing the Van-der-Waals volumes of $C_{60}$ and $\mathrm{C}_{70}$ and the size of the cavity within the complex. While $\mathrm{C}_{60}$ takes up only about $40 \%$ of the volume of the cavity $\left(547 \AA^{3}\right) C_{70}$ takes up about $50 \%\left(646 \AA^{3}\right)^{[20]}$ of the cavity. This is closer to the optimum of $55 \pm 9 \%$ occupation in host-guest complexes. ${ }^{[21]}$ More than $90 \%$ of the cages are thus filled with $\mathrm{C}_{70}$ as proven by NMR specrtroscopy.

We furthermore investigated the association of $\mathrm{C}_{70}$ in $[\mathrm{Zn}-2]$ by means of DFT calculations according to our standard protocol. ${ }^{[22 a]}$ Since these calculations are very challenging for systems of this size, we made use of a newly developed tightbinding method for structure optimizations and harmonic frequency calculations. ${ }^{[22 b, c]}$ With a computed free energy $\Delta G$ of $-26.2 \mathrm{kcal} \mathrm{mol}^{-1}$ in solution, $\mathrm{C}_{70}$ is strongly bound, which is the largest affinity that we computed for any supramolecular complex (for details refer to the $\mathrm{SI}$ ). Even though this value bears some uncertainty, due to the high charge and the approximate treatment of the molecular environment (implicit solvation, missing counter-ions), this strong affinity shows the high potential of this host for binding large aromatic guests.

We determined the magnetic susceptibility of the iron complexes employing both the original Evans' method ${ }^{[23]}$ and the more modern ideal solution model. ${ }^{[24,25]}$ NMR-based methods are best suited to examine magnetic properties of complex supramolecular systems in the absence of packing effects ${ }^{[13]}$ and allow examination of mixtures of substrates based on their chemical shifts as well as the bulk properties by observing diamagnetic probe molecules (Figure 3 and $\mathrm{SI}) .{ }^{[26]}$

At $298 \mathrm{~K}$ the magnetic moment $(\chi \mathrm{T})$ of $[\mathrm{Zn}-1]$ is $20.8 \mathrm{~cm}^{3} \mathrm{~K} \mathrm{~mol}^{-1}$ (based on the ideal solution model) and $20.1 \pm 0.2 \mathrm{~cm}^{3} \mathrm{~K} \mathrm{~mol}^{-1}$ (based on Evan's method), ${ }^{[27]}$ which translates to an equivalent of $86 \%$ of uncoupled iron(II) centers ${ }^{[28]}$ being in high-spin configuration, matching chemical shifts of $143 \mathrm{ppm}$ for the imine protons. ${ }^{[29]}$ Although not being perfectly comparable this proportion could furthermore be validated by Mössbauer spectroscopy in solid state. In a powdered sample of [Zn-1] the amount of metal centers in the high-spin configuration was measured to be $90 \%$ at $298 \mathrm{~K}$ (see $\mathrm{SI}$ ). For $\left[\mathrm{H}_{2}-1\right]$ similar values of $18.8 \mathrm{~cm}^{3} \mathrm{~K} \mathrm{~mol}^{-1}$ (ideal solution model) and $19.2 \pm 0.3$ $\mathrm{cm}^{3} \mathrm{~K} \mathrm{~mol}^{-1}$ (Evans' method) were obtained. ${ }^{[27]}$

Upon cooling a typical sigmoid transition curve of the chemical shifts can be observed which is practically identical for both $\left[\mathrm{H}_{2}-1\right]$ and $[\mathrm{Zn}-1]$. A similar behavior in solid state could again be observed by Mössbauer spectroscopy in [Zn-1], revealing a distribution of $35 \%$ high-spin to $65 \%$ low spin at $160 \mathrm{~K}$ and finally $30 \% \mathrm{HS}$ to $70 \% \mathrm{LS}$ at $80 \mathrm{~K}$.

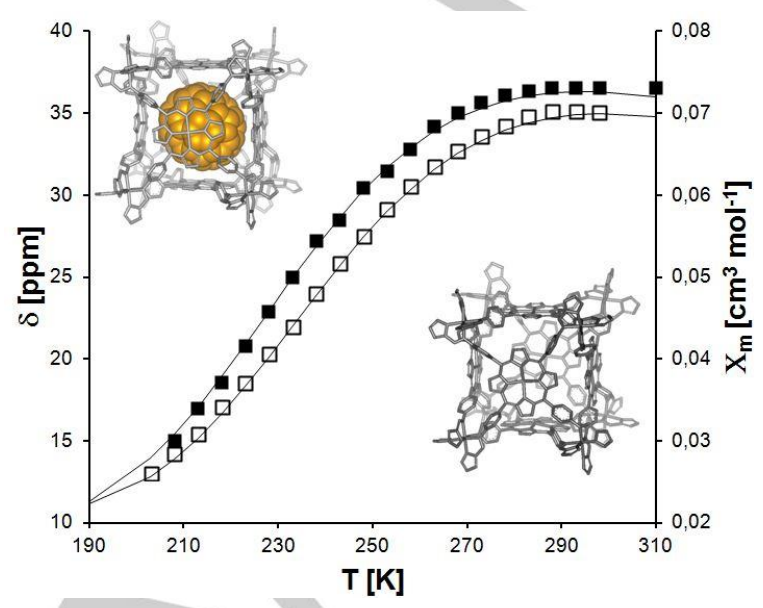

Figure 3: Shifts of selected protons in temperature dependent ${ }^{1} \mathrm{H}-\mathrm{NMR}$ experiments in $\mathrm{MeOH}-d_{4}$. Empty squares [Zn-1], black squares $\mathrm{C}_{70} @[\mathrm{Zn}-1$ ] and calculated molar susceptibility $X_{m}$ based on the ideal solution model (black lines, scaled).

Table 1: Thermodynamic parameters of the spin transition obtained by the ideal solution model (see SI for details)

\begin{tabular}{rccc}
\hline & $\Delta \mathrm{H}\left(\mathrm{kJ} \mathrm{mol}^{-1}\right)$ & $\Delta \mathrm{S}\left(\mathrm{J} \mathrm{mol}^{-1} \mathrm{~K}^{-1}\right)$ & $\mathrm{T}_{1 / 2}(\mathrm{~K})$ \\
\hline$\left[\mathrm{H}_{2}-1\right]$ & $19.7 \pm 0.5^{*}$ & $78.9 \pm 2.5$ & 249.6 \\
$\mathrm{C}_{70} @\left[\mathrm{H}_{2}-1\right]$ & $19.5 \pm 0.5$ & $84.7 \pm 2.2$ & 229.9 \\
{$[\mathrm{Zn}-1]$} & $21.3 \pm 0.4$ & $86.2 \pm 2.0$ & 247.7 \\
$\mathrm{C}_{70} @[\mathrm{Zn}-1]$ & $21.1 \pm 0.4$ & $89.2 \pm 1.7$ & 236.3 \\
\hline
\end{tabular}

* uncertainty calculated for $2 \sigma$

Furthermore, another supramolecular effect on the magnetic properties could be observed. The inclusion of guests results in a stabilization of the high-spin state in the iron complexes $\left[\mathrm{H}_{2}-1\right]$ and $[\mathrm{Zn}-1]$. As shown by ${ }^{1} \mathrm{H}-\mathrm{NMR}$-spectroscopy, two distinct species can be observed in the case of $\mathrm{C}_{60}$. With only about $50 \%$ of the cages accommodating guests this is in very good agreement with the host-guest behavior of [ $\mathrm{Zn}-2]$ and $\left[\mathrm{H}_{2}-2\right]$. As noted above, more than $90 \%{ }^{[30]}$ of the complexes accommodate a guest in the case of $\mathrm{C}_{70}$ with no observable exchange on the NMR timescale, making this host-guest complex a feasible subject for a more detailed study. At $298 \mathrm{~K}$ increased magnetic moments of $21.6 \mathrm{~cm}^{3} \mathrm{~K} \mathrm{~mol}^{-1}$ (ideal solution model, $\mathrm{C}_{70} @[\mathrm{Zn}-1]$ ) and $19.6 \mathrm{~cm}^{3} \mathrm{~K} \mathrm{~mol}^{-1}$ (ideal solution model, $\left.\mathrm{C}_{70} @\left[\mathrm{H}_{2}-1\right]\right),{ }^{[27]}$ equivalent to an increased population of the high-spin state of roughly $3 \%$, were observed. Upon cooling a significantly different behavior can be observed (Figure 4). The high-spin state is significantly stabilized as shown by a higher susceptibility and a lower transition temperature $T_{1 / 2}$ of the spin transition. The spin transition is delayed upon cooling by $15 \mathrm{~K}$ for $\mathrm{C}_{70} @[\mathrm{Zn}-1]$ and even $20 \mathrm{~K}$ for $\mathrm{C}_{70} @\left[\mathrm{H}_{2}-1\right]$. At $200 \mathrm{~K}$ the limit of the NMR-spectrometer was reached but the data clearly establishes the low-spin stabilization by supramolecular encapsulation of $\mathrm{C}_{70}$ in the cavity of the spin-crossover complex. By analyzing a one-to-one mixture of empty and filled cages we could establish that the observed spin transition of one 
compound is not affected by the other compound in solution. Interestingly, analysis of these data according to the ideal solution model revealed that the stabilization is entropically driven rather than a result of enthalpic factors (see Table 1 and SI).

In conclusion, we have synthesized and characterized a series of octanuclear supramolecular cages. The systems were characterized using single crystal XRD analysis, a broad variety of NMR techniques including Evans' method, the ideal solution model and 2D techniques, Mössbauer spectroscopy, high resolution mass spectrometry, UV/Vis- and FT-IR-spectroscopy as well as DFT methods to determine the structure of the metallosupramolecular assembly and its host-guest complexes as well as its magnetic behavior. These systems are both capable of binding large aromatic guests and the iron(II) cages are also capable of showing spin-crossover in solution, thus, being an intrinsic property of the cationic octanuclear complex rather than a solid state phenomenon. Interestingly, encapsulation of large aromatic guests within the assemblies' cavities stabilize the high-spin state most likely by entropic effects. The observed transition temperature was shifted by up to $20 \mathrm{~K}$ offering another handle to affect the spin-crossover properties next to the commonly found ways of crystal engineering and ligand design. This approach might lead to a better predictability and tunability of spin-crossover compounds.

\section{Acknowledgements}

Financial support from the Deutsche Forschungsgemeinschaft (DFG) (SFB813 - Chemistry at Spin Centers) and the Academy of Finland (K.R.: project no's. 263256, 298817 and 265328) is gratefully acknowledged. N.S. thanks the Evonik Foundation for a doctoral scholarship. We thank Diamond Light Source, UK for time on Beamline I19 (MT11397).

Keywords: metallosupramolecular chemistry • self-assembly • host guest chemistry $\bullet$ spin-crossover $\bullet$ iron(II) complexes

[1] a) M. A. Halcrow (Ed.), Spin-Crossover Materials, Wiley, Chichester, UK, 2013; b) P. Gütlich, H. A. Goodwin (Eds.), Spin Crossover in Transition Metal Compounds IIII, Topics in Current Chemistry, Springer, Berlin, 2004, Vol. 233-235; c) P. Gütlich, Y. Garcia, H. Spiering, in Magnetism: Molecules to Materials IV (Eds.: J. S. Miller, M. Drillon), Wiley-VCH, Weinheim, Germany, 2002, p. 271-344.

[2] a) P. Gütlich, A. Hauser, H. Spiering, Angew. Chem. Int. Ed. 1994, 33, 2024-2054; Angew. Chem.1994, 106, 2109-2141; b) P. Gütlich, Y. Garcia, H. A. Goodwin, Chem. Soc. Rev. 2000, 29, 419-427; c) P. Gütlich, P. J. van Kiningsbruggen, F. Renz, Struct. Bonding 2004, 107 27-75; d) A. B. Gaspar, V. Ksenofontov, M. Serednyuk, P. Gütlich, Coord. Chem. Rev. 2005, 249, 2661-2676; e) A. Bousseksou, G. Molnár, J. A. Real, K. Tanaka, Coord.Chem. Rev. 2007, 251, 18221833; f) K. S. Murray, Eur. J. Inorg.Chem. 2008, 3101-3121; g) J. Kitchen, S. Brooker, Coord. Chem. Rev. 2008, 252, 2072-2092; h) J. Olguin, S. Brooker, Coord. Chem. Rev. 2011, 255, 203-240.

[3] W. Lu, C. M. Lieber, Nat. Mater.2007, 6, 841 - 850.

[4] C. J. Sumby, Coord. Chem. Rev. 2011, 255, 1937-1967.

[5] a) A. B. Gaspar, M. C. Munoz, J. A. Real, J. Mater. Chem. 2006, 16, 2522-2533; b) M. H. Klingele, B. Moubaraki, J. D.
Cashion, K. S. Murray, S. Brooker, Chem. Commun. 2005, 987-989; c) G. S. Matouzenko, E. Jeanneau, A. Y. Verat, A. Bousseksou, Dalton Trans. 2011, 40, 9608-9618; d) J. A. Real, Bistability in Iron(II) SpinCrossover Systems: A Supramolecular

Function, in: Perspectives in Supramolecular Chemistry: Transition Metals in Supramolecular Chemistry, vol. 5 (Ed.: J.-P. Sauvage), Wiley, Chichester, UK, 1999; e) C. F. Herold, L. M. Carella, E. Rentschler, Eur. J. Inorg.Chem. 2015, 3632-3636; f) D. Lewing, H. Koppetz, F. E. Hahn, Inorg. Chem. 2015, 54, 7653-7659.

[6] a) F. Tuna, M. R. Lees, G. J. Clarkson, M. J. Hannon, Chem. Eur. J. 2004, 10, 5737-5750; b) D. Pelleteret, R. Clérac, , C. Mathonière, E. Harté, W. Schmitt, P. E. Kruger, Chem. Commun. 2009, 221-223; c) L. J. Charbonnière, A. F. Williams, C. Piguet, G. Bernardinelli, E. RivaraMinten, Chem. Eur. J. 1998, 4, 485-493; R. J. Archer, C. S. Hawes, G. N. L. Jameson, V. McKee, B. Moubaraki, N. F. Chilton, K. S. Murray, W. Schmitt, P. E. Kruger, Dalton Trans. 2011,40, 12368-12373.

[7] E. Breuning, M. Ruben, J.-M. Lehn, F. Renz, Y. Garcia, V. Ksenofontov, P. Gütlich, E. Wegelius, K. Rissanen, Angew. Chem. Int. Ed.2000, 39 , 2504-2507, Angew.Chem.2000, 114, 2563-2566; b) D. Y. Wu, O. Sato, Y. Einaga, C.-Y.Duan, Angew. Chem. Int. Ed. 2009, 48, 1475-1776. Angew.Chem.2009, 121, 1503-1506; c) M. Ruben, J. Rojo, F. RomeroSalguero, L. H. Uppadine, J.-M. Lehn, Angew. Chem. Int. Ed. 2004, 43, 3644-3662, Angew. Chem.2004, 116, 3728-3747; d) F. Li, J. K. Clegg, L. Goux-Capes, G. Chastanet, D. M. D'Allesandro, J. F. Létard, C. J. Kepert, Angew. Chem. Int. Ed. 2011, 50, 2820-2823, Angew. Chem.2011, 123, 2872-2875; e) M. Steinert, B. Schneider, S. Dechert, S. Demeshko, F. Meyer, Angew. Chem. Int. Ed. 2014, 53, 6135-6139, Angew. Chem. 2014, 126, 6249-6253. f) T. Matsumoto, G. N. Newton, T. Shiga, S. Hayami, Y. Matsui, H. Okamoto, R. Kumai, Y. Murakami, H. Oshio, Nat. Commun. 2014, 5, 3865.

[8] A. Ferguson, M. A. Squire, S. Siretanu, D. Mitcov, C. Mathonière, R Clérac, P. E. Kruger, Chem. Commun, 2012, 49, 1597-1599; b) R. A Bilbesi, S. Zarra, H. L. C. Feltham, G. N. L. Jameson, J. K. Clegg, S Brooker, J. R. Nitschke, Chem. Eur. J. 2013, 19, 8058-8062; c) L. Li, N. Saigo, Y. Zhang, D. J. Fanna, N. D. Shepherd, J. K. Clegg, R. Zheng, S. Hayami, L. F. Lindoy, J.-R. Aldrich-Wright, C.-G. Li, J. K. Reynolds, D. G. Harman, F. Li, J. Mat. Chem. C., 2015, 3, 7878-7882.

[9] C. Piguet, E. Rivara-Minten, Helv. Chim.Acta1995, 78, 1651-1672; b) C. Piguet, E. Rivara-Minten, G. Bernardinelli, J.-G. Bünzli, G. Hopfgartner, J. Chem. Soc., Dalton Trans. 1997, 421-433; c) C. Edder, C. Piguet, G. Bernadinelli, J. Mareda, C. G. Bochet, J.-C. G. Bünzli, G. Hopfgartner, Inorg. Chem. 2000, 39, 5059-5073; d) C. Edder, C. Piguet, J.-C. G. Bünzli, G. Hopfgartner, Chem. Eur. J. 2001, 7, 3014-3024.

[10] K. Ono, M. Yoshiwaza, M. Akita, T. Kato, Y. Tsunobuchi, S.-I.Ohkoshi, M. Fujita, J. Am. Chem. Soc. 2009, 131, 2782-2783.

[11] A. M. Castilla, W. J. Ramsay, J. R. Nitschke, Acc. Chem. Res.2014, 47, 2063-2073

[12] a) F. Reichelt, J. K. Clegg, K. Gloe, K. Gloe, J. J. Weigand, J. K. Reynolds, C.-G. Li, J. R. Aldrich-Wright, C. J. kepert, L. F. Lindoy, H.-C. Yao, F. Li, Inorg. Chem. 2014, 53, 688 - 690; b) Feng Li, N. F. Sciortino, J. K. Clegg, S. M. Neville, C. J. Kepert, Aust. J. Chem. 2014, 67, 16251628; c) A. Ferguson, R. W. Staniland, C. M. Fitchett, M. A. Squire, B. E. Williamson, P. E. Kruger, Dalton Trans. 2014, 43, 14550-14553.

[13] a) P. Gütlich, Eur. J. Inorg. Chem., 2013, 581 - 591; b) P. N. Martinho, Y. Ortin, B. Gildea, C. Gandolfi, G. McKerr, B. O'Hagan, M. Albrecht, G G. Morgan, Dalton Trans. 2012, 41, 7461 - 7463.

[14] W. Meng, B. Breiner, K. Rissanen, J. D. Thoburn, J. K. Clegg, J. R. Nitschke, Angew. Chem. Int. Ed. 2011, 50, 3479-3483, Angew. Chem.2011, 123, 3541 - 3545.

[15] a) S. Grimme, J. Chem. Phys. 2013, 138, 244104. b) C. Bannwarth, S Grimme, Comp. Theor. Chem. 2014, 1040-1041, 45.

[16] a) S. Grimme, J. G. Brandenburg, C. Bannwarth, A. Hansen, J. Chem. Phys. 2015, 143, 054107. b) R. Ahlrichs, M. Bär, M. Häser, H. Horn, C. Kölmel, Chem. Phys. Lett. 1989, 162, 165. c) TURBOMOLE, version 7.0: TURBOMOLE $\mathrm{GmbH}$, Karlsruhe 2015. See http://www.turbomole.com. 
[17] We encountered several drawbacks such as a high degree of disordered counter-ions, a huge cavity of about $1300 \AA^{3}$ in the center of the complex, disordered solvent molecules, twinning, volatile crystals as well as a general tendency to not crystallize well just left us with a fair set of crystallographic data. An exact structural analysis of bond lengths could not be carried out based on the data. Nevertheless, the data proves the overall structure of the complex.

[18] The volume can be easily estimated by assuming a cubic void and using the distance of two opposing zinc atoms minus $3.4 \AA$ for the $\pi$ systems as edge length resulting in a volume of $1289 \AA^{3}$. This estimation matches the data reported in Ref. 15

[19] Encapsulation also occurs using the preformed octanuclear metallosupramolecular aggregate. However, encapsulation was found to take a much longer time

[20] G. B. Adams, M. O'Keefe, R. S. Ruoff, J. Phys. Chem. 1994, 98, 94659469.

[21] S. Mecozzi, J. Rebek, Jr., Chem. Eur. J. 1998, 4, 1016-1022.

[22] a) S. Grimme Chem. Eur. J. 2012 18, 9955-9964; b) S. Grimme, C Bannwarth J. Chem. Phys. 2016, 145, 054103; c) S. Grimme, C. Bannwarth, P. Shushkov, J. Chem. Theor. Comput., submitted.

[23] D. F. Evans, J. Chem. Soc. 1959, 2003-2005, b) D. H. Live, S. I. Chan, Anal. Chem.1970, 42, 791-792, c) C. Piguet, J. Chem. Educ. 1997, 74 815-816.

[24] W. Kläui, W. Eberspach, P. Gütlich, Inorg. Chem. 1987, 26, 3977-3982.

[25] For some applications of the ideal solution model see: a) S. G. Telfer, B. Bocquet, A. F. Williams, Inorg. Chem. 2001, 40, 4818-4820; b) A Ferguson, M. A. Squire, D. Sireatnu, D. Mitcov, C. Mathonière, R. Clérac, P. E. Kruger, Chem. Commun. 2013, 49, 1597-1599; c) J. Travieso-Puente, J. O. P. Broekman, M.-C. Chang, S. Demeshko, F. Meyer, E. Otten, J. Am. Chem. Soc. 2016, 138, 5503-5506.

[26] a) I. Bertini, C. Luchinat, G. Parigi, Prog.Nucl.Magn. Res.Spectros.2000, 40, 249-273, b) W. C. Isley III, S. Zarra, R. K. Carlson, R. A. Bilbesi, T. K. Ronson, J. R. Nitschke, L. Gagliardi, C. J. Cramer, Phys. Chem. Chem. Phys, 2014, 16, 10620-10628.

[27] Please note, that the calculated errors for the original Evans' method are based on the Gaussian's law of error propargation. The statistical values for the ideal solution model are given in Table 1.

[28] The spin-only value per uncoupled iron(II) center with $\mathrm{S}=2$ and $\mathrm{g}=2$ would be $3.001 \mathrm{~cm}^{3} \mathrm{~K} \mathrm{~mol}^{-1}$ which is in very good agreement with previously reported data but the exact value can differ with the used system.

[29] W.C. Isley III, S. Zarra, R. K. Carlson, R. A. Bilbesi, T. K. Ronson, J. R. Nitschke, L. Gagliardi, C. J. Cramer, Phys. Chem. Chem. Phys. 2014, 16, 10620-10628

[30] Effectively the analytical limit set for determination by NMR spectroscopic means for paramagnetic samples. 


\section{Entry for the Table of Contents}

Layout 1:

\section{COMMUNICATION}

Porphyrin-based octanuclear metallosupramolecular cages were prepared via subcomponent self-assembly and structurally characterized by a broad variety of experimental and theoretical means. Interestingly the iron(II) cages undergo spin-crossover in solution. This behavior is guest dependent as encapsulation of fullerene $\mathrm{C}_{70}$ stabilizes the high-spin state shifting the spin-transition temperature by as much as $20 \mathrm{~K}$.

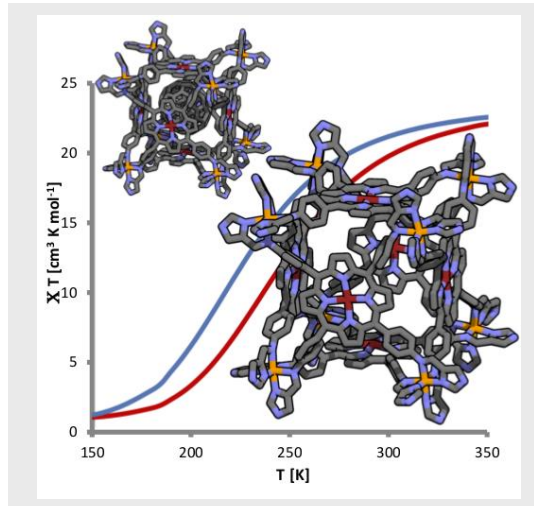

Niklas Struch, Christoph Bannwarth, Tanya R. Ronson, Yvonne Lorenz, Bernd Mienert, Norbert Wagner, Marianne Engeser, Eckhard Bill, Rakesh Puttreddy, Kari Rissanen, Johannes Beck, Stefan Grimme, Jonathan R. Nitschke, and Arne Lützen*

Page No. - Page No.

An Octanuclear Metallosupramolecular Cage Designed to Exhibit Spin-Crossover Behavior 